\title{
Investigating the Relationship Between Vocabulary Knowledge and FL Speaking Performance
}

\author{
Thamer Alharthi ${ }^{1}$ \\ ${ }^{1}$ Department of European Languages and Literature, King Abdulaziz University, Jeddah, Saudi Arabia \\ Correspondence: Thamer Alharthi1, P. O. BOX 80200, Jeddah 21589, Saudi Arabia. E-mail: \\ talharthi@kau.edu.sa
}

Received: September 12, 2019 Accepted: October 13, 2019 Online Published: December 10, 2019

doi:10.5539/ijel.v10n1p37 URL: https://doi.org/10.5539/ijel.v10n1p37

\begin{abstract}
Research has highlighted the importance of vocabulary learning in order for L2 learners to cope with the linguistic demands of fundamental skills such as reading and listening. However, few empirical studies have investigated the relative strength of the association of a specific construct of vocabulary knowledge has on the skill of speaking. To understand more fully the practical implications of such a relationship, this paper presents empirical evidence gathered to explore a measure of productive vocabulary knowledge and the degree to which this measure correlates with and is able to predict speaking success. A cohort of 18 sophomore university learners of English as a foreign language (EFL) in Saudi Arabia (SA) completed the Productive Vocabulary Levels Test (PVLT), an oral interview and a speaking task. Test scores derived from PVLT were analyzed to produce a range of descriptive statistics, which underwent correlational analyses to determine the relationship between the measure of PVLT and speaking success. Analyses revealed a consistent pattern of declining scores from the highest to the least frequent word levels. A closer examination of the data showed that the participants' success across the five-word levels of the PVLT showed better performance on the 2,000 and 3,000-word levels, in fact, the results indicated that only these word levels made a contribution to predicting speaking scores. Based on these findings, we draw implications for vocabulary teaching contexts and provide suggestions for future studies on vocabulary and speaking link.
\end{abstract}

Keywords: speaking, oral interview, conversation task, vocabulary, EFL classroom

\section{Introduction}

It has been acknowledged for some time that vocabulary knowledge and its acquisition have the power to predict proficiency and language use (Milton, 2013; Nation, 2013). The commonsense view of vocabulary assessment is to address this knowledge in the four separate skills, i.e., reading and listening (receptive skills) and writing and speaking (productive skills) (Fitzpatrick \& Clenton, 2017). Many L2 vocabulary researchers have highlighted the potential relationship between vocabulary knowledge and the ability to read, write and listen in the target language (e.g., Alharthi, 2018, 2019; Laufer \& Aviad-Levitzky, 2017; Stæhr, 2009; Wang \& Treffers-Daller, 2017). With the exception of De Jong, Steinel, Florijn, Schoonen, and Hulstijn (2012), Koizumi and In'nami (2013), Milton, Wade, and Hopkins (2010) and Uchihara and Clenton (2018), it is almost certain that no study has attempted to examine the association between vocabulary knowledge and ability to speak in a Saudi setting. It would therefore be of interest and importance to look at the effect of lexical knowledge on speaking performance. English language competence is currently one of the essential requirements for applicants for new posts in various business enterprises and the government sector, and when employers consider promotion for their employees in Saudi Arabia (SA). In the light of these demands, it is vital that many Saudi EFL teachers start to focus on the learners' speaking skills, e.g., by employing role plays and group discussions as useful ways to help learners increase their oral communication skills and their confidence in speaking.

It is generally agreed that people's ability to use language, and thus vocabulary, is a crucial element of language knowledge necessary for successful communication. Further, it is assumed that vocabulary knowledge specifically contributes to L2 learners' success in decoding a variety of contextual information when reading or listening to texts. However, having both ability and vocabulary knowledge does not necessarily translate to speaking since L2 learners' reticence often prevents them from using the target language. Among the factors which lead to a learner's reticence in the classroom is the vocabulary that is accessible to them as part of their 
lexical repertoire. This is especially so in FL contexts where learners prefer to be silent or sit back in the classroom to avoid participation in activities that push them to speak. Nation (2001) argues that L2 learners are sometimes having difficulties expressing their intended meanings because they lack sufficient lexical knowledge or are unable to fully use their vocabulary knowledge in oral interaction. Of course, there is a lot involved in learning a lexical item, as shown in the authoritative taxonomy of vocabulary knowledge described in influential books by Nation (2001), Read (2000), Schmitt (2010) and Milton (2009). The authors seem to agree that vocabulary knowledge should be viewed as a multidimensional construct consisting of a set of features such as definition, collocation, orthographic, phonological and grammatical dimensions. While it is agreed that the form-meaning link is a principal step in acquiring vocabulary knowledge through both understanding and producing written text, there are other types of vocabulary knowledge, e.g., knowledge of word form, word meaning and word use, each of which is further described in terms of both receptive and productive modes, and in both written and spoken form (see Nation, 2001 for specification of the range of word knowledge aspects).

\section{Research Evidence of L2 Vocabulary Knowledge and Speaking Performance}

Undeniably vocabulary knowledge is a good and reliable predictor of proficiency and performance, including of reading, listening and writing (Alharthi, 2016; Milton, Wade, \& Hopkins, 2010; Sonbul \& Schmitt, 2010; Stæhr, 2009). Although links have been well established between lexical knowledge and the above L2 language skills, there has been a relatively dearth of studies addressing the acquisition of oral vocabulary through spoken input (Schmitt, 2014). It is the nature and extent of this link that the current research explores. A common conception of vocabulary knowledge entails the distinction between breadth/size (how many words a learner knows) and depth/quality (how well a learner knows a particular word) (Anderson \& Freebody, 1981). It is crucial to note that an estimate of vocabulary load is needed, especially in FL education settings where such information benefits oral courses such as speaking to help instructors and course writers in setting adequate goals for optimal vocabulary learning. The literature assumes a threshold of 2,000-5,000 vocabulary items to be the minimum learning target in order for an L2 learner to pleasurably comprehend reading texts (Hirsh \& Nation, 1992; Laufer, 1997). For the L2 learner to gain knowledge of spoken English, a vocabulary size of 6,000-7,000-word families may be necessary (Nation, 2006). However, it is possible that a large vocabulary such as that implied by Nation's figure is more appropriate to reading and writing rather than speaking. This view was put by Adolphs and Schmitt (2003) whose analysis of spoken data found that a 95\% coverage of the demands of conversational English could be reached with a vocabulary of 2,000 to 3,000 words. It should be noted that the correlation between vocabulary size and speaking ability is not as straightforward as this suggests and may in fact be difficult to establish. The lack of such a relationship might be due to the learner's L2 proficiency, the influence of the learner's L1 background and the skills the learner needs e.g. asking for directions (Milton, 2013). A further complication is the importance of knowing the most frequent words at the 2,000-word level. Stæhr (2009) provides considerable evidence that knowledge of 2,000 words is an important threshold for learners to score a grade 5 or better on formal tests such as the International English Language Testing System (IELTS) listening and speaking tests. Following the same line of thinking, Milton (2013) reviewed research that explored the contribution of vocabulary size to aural and oral performance and concluded that a vocabulary size at the 2,000 to 3,000-word levels was a crucial learning goal to bring about an improvement in L2 learners' oral interaction. In other words, a typical oral discourse was shown to comprise relatively few unique words but that these were (1) of high frequency, (2) likely to be familiar to L2 learners and (3) sufficient for oral interaction. As a learner becomes competent in the target language, then generally more lexical items are known and produced. Few researchers have attempted to elicit highly proficient, i.e., fluent, L2 learners' word knowledge using productive measurements. De Jong, Steinel, Florijn, Schoonen, and Hulstijn (2012) examined the role of productive vocabulary knowledge in L2 speaking performance, using various assessments to measure productive accuracy of grammar and pronunciation by 181 adult learners of Dutch at upper-intermediate and advanced levels. The results revealed that the learners' single lexical item forms, which implied size of vocabulary knowledge together with depth and intonation measurements, were predictors of overall speaking competency. Using L1-L2 translation tasks, Koizumi and In'nami (2013) sought to specify the degree to which L2 speaking proficiency can be predicted by a number of oral features, namely fluency, accuracy and grammatical construct, by 87 novices to intermediate Japanese learners of English. They concluded that speaking performance can be explained by vocabulary knowledge to a considerable degree, ranging from $32 \%$ to $88 \%$ and therefore the construct of vocabulary knowledge was a strong predictor of EFL learners' oral abilities. Milton, Wade, and Hopkins (2010) investigated the contribution of vocabulary knowledge using computerised Yes/No tests to measure orthographic, X-Lex (Meara \& Milton, 2003) and phonological, A-Lex (Milton \& Hopkins, 2006) vocabulary size. The results were compared with 30 EFL learners' scores obtained from IELTS tests to explain performance in all four language skills. The authors reported a significant correlation of $(\mathrm{r}=.71)$ between vocabulary size in aural 
format and IELTS scores for speaking, indicating that vocabulary size can predict L2 speech production. In their most recent study, Uchihara and Clenton (2018) explored the relationship between vocabulary size and L2 speaking proficiency for 46 advanced learners in a rich immersive L2 learning setting. Learners' receptive vocabulary size was measured via a Yes/No task (Meara \& Miralpeix, 2017) and their lexical use via a picture narrative task. According to Pearson correlation analyses carried out, there was a significant correlation $(\mathrm{r}=.55)$ between receptive vocabulary size and the range of vocabulary items produced in the spontaneous narrative task. The findings also suggest that as the participants scored a vocabulary size of 6,000 words on average, they are more likely to be lexically proficient in their speaking ability.

\section{Key Issues with Specific Attention to the Current Study}

A review of previous research into the relationship between vocabulary knowledge and speaking ability yields important conclusions (De Jong, Steinel, Florijn, Schoonen, \& Hulstijn, 2012; Koizumi \& In'nami, 2013; Milton, Wade, \& Hopkins 2010; Uchihara \& Clenton 2018). With little evidence to provide a predictive value of vocabulary size for L2 speaking ability, this topic merits further attention and exploration by vocabulary researchers. The above-mentioned studies point to the construct of productive vocabulary knowledge by employing checklists for a vocabulary test. Although such instruments are practical and the tests easy to take, there is a $25-33 \%$ possibility of blind guessing in the sense that test takers respond to target items that they do not know and researchers thus overestimating the learners' vocabulary knowledge. These studies have consistently presented a correlation between a given L2 vocabulary size and speaking ability, for example by using Yes/No tests which target recognition of vocabulary items. Such a measurement proved to be problematic as it did not present a concise picture of the relationship construct of productive vocabulary knowledge and L2 production skill. This is not to denigrate the value of the Yes/No tests, but our view is that productive vocabulary knowledge can be better estimated by a more accurate and reliable tool. The present study therefore will investigate whether vocabulary knowledge is a strong indicator of speaking proficiency using a well-constructed measure, namely the Productive Vocabulary Levels Test (PVLT) (Laufer \& Nation, 1999) which allows learners to demonstrate their lexical knowledge more representatively. Moreover, speaking performance was assessed in the existing studies as part of self-human rating (De Jong, Steinel, Florijn, Schoonen, \& Hulstijn, 2012; Koizumi \& In'nami, 2013), using scores for speaking obtained from international assessments, e.g., IELTS (Milton, Wade, \& Hopkins, 2010; Stæhr, 2009), or a combination of self-human rating and a picture narrative task (Uchihara \& Clenton, 2018). Instead, the present study assesses learners' oral performance through a one-on-one interview which is believed to be a valid testing instrument for this particular variable (Schmitt, 2010). Furthermore, the present study elicits learners' speech samples through a speaking task adopted from classroom course materials. Based on the literature and the limitations outlined above, the following research questions were formulated:

To what extent does vocabulary size, measured via PVLT, of the present participants correlate with their speaking performance?

Will the effect of vocabulary size on the present participants' speaking performance be the same across different types of speaking tasks?

\section{Methodology}

\subsection{Participants and Setting}

The sample of participants in the current study comprised 18 tertiary level EFL students at a large university, King Abdulaziz University (KAU) in Saudi Arabia (SA). All participants were undergraduates majoring in an English degree and assigned to the upper-intermediate level of English-B1, based on a measurement of language ability such as the Common European Framework of Reference (CEFR), which they had to obtain upon enrollment in the BA course. During their first two academic years, students had to register for two 3-credit hours of compulsory modules titled Listening \& Speaking I and Listening \& Speaking II, which was done prior to the current research. The modules comprised lectures and seminars based on a communicative approach in which English was used as the medium of instruction at all times and where students had to communicate with their teachers in English. The classes were normally assigned to native Arabic-speaking teachers who had studied in English speaking countries for more than four years prior to their arrival in SA. The modules covered lexical and grammatical aspects of English as well as practice-oriented group discussions to specifically develop students' competence in listening and speaking. The participants took part in the study on a voluntary basis which was one of the ethical issues strictly followed in accordance with the standards set by the human subject review board at KAU. 


\section{Research Instruments}

\subsection{Productive Vocabulary Levels Test (PVLT)}

To predict the learners' productive vocabulary size, the researcher chose the PVLT (Laufer \& Nation, 1999) as a measuring tool that met the research requirements for accuracy and reliability. The PVLT was chosen as it had been proficiently constructed and extensively used as a reliable tool in vocabulary research in education with the aim of evaluating word knowledge and implementing comprehension interventions (Schmitt, 2008). The PVLT used the same frequency lists as those used in the Vocabulary Levels Test (VLT) for receptive vocabulary knowledge. The PVLT sampled vocabulary at five frequency levels: 2,000, 3,000, 5,000, 10,000, and academic word levels, with 18 words from each of the five frequency levels tested. It is a discrete-point test based on a controlled task format that requires test takers to read a contextualized sentence within which a target word has to be completed. To remove ambiguity or unpredictable answers, the first letters are given within the blank space.

\subsection{One-on-One Interview}

To estimate the learners' speaking performance, two separate measures were operationalised via a two-step assessment approach. The first step taps the test takers' linguistic knowledge, with emphasis on lexical knowledge, through a 10-minute oral interview with the present researcher. In other words, the task was not set up as a conversational setting but as an interview setting. To measure the interviewees' oral performance, they were given a list of 10 target words randomly selected from the PVLT relevant frequency bands. Following Schmitt, Schmitt and Clapham (2001), each interviewee was asked to look at the list of words and describe their meaning one by one. Such in-depth interviews were meant to determine the participants' speaking proficiency using their knowledge of the target words used in the PVLT (Schmitt, 2010). For example, the word delivery means the act of transferring something; therefore, interviewees were expected to provide more information such as different uses and contexts where this word can occur.

\subsection{Conversation Task}

The second step involves a spoken stimulus speech which aims to tap more exclusively the participants' lexical knowledge. The task was adopted from the speaking exercises found in the speaking materials of their English course, so presumably they were familiar with this type of task and no difficulties in understanding or formulating answers to them were reported. Each participant was asked to talk about his university life, personal experience, interests and future plans after university. This would elicit familiar information and prompt natural with as close to real-life speech as possible. Eventually, the rationale of using a combination of these discrete-point vocabulary tests as well as the objective speaking tasks was to provide enough and valid information about the participants' oral ability with a limited emphasis on vocabulary knowledge.

\section{Procedure}

Written consent forms were obtained from all participants who were also informed that they could withdraw at any time without penalty. Those who took part in the study earned extra credits in their relative courses. As the present study consisted of a number of speaking tasks and a vocabulary test, the researcher thought that a language lab was more suitable, mainly to avoid the noise and distractions that are common in a normal classroom. Moreover, the participants were familiar with the setting of the language lab as they had taken Listening and Speaking I and II modules at the time of the study. The research instruments were administered in three phases: the PVLT at the beginning in a single session which was a part of their regular English class. Nation and Webb (2011) argued that the amount of time was a variable that was likely to influence the results of the vocabulary test, hence participants were permitted to take as much time as needed to complete the test. The interview sessions were conducted individually, with each participant invited to a single setting with the present researcher, with each session taking approximately 10 minutes. Finally, the conversation task was assessed independently, with roughly 10 minutes set aside for each session. The reason for setting a time limit for the speaking tasks was to echo the oral assessment requirements set by the English Department (ED) entrance examination for future English majors. The maximum score for the PVLT was 90, based on 1 point per correct word. Following Laufer and Nation (1999), accurate spelling of each target item was not important as long as it was understandable. SPSS Statistics 20.0 for Windows was used for the PVLT data analysis to produce a range of descriptive and correlational statistics. A digital audio recorder was placed on the desk right in front of each interviewee. The grading criteria of the speaking tasks were adapted from the in-house (ED) entrance examination (oral part) for EFL learners. Five categories were applied to contribute to the overall scores of the speaking tasks: content (20\%), vocabulary $(20 \%)$, grammar (20\%), fluency $(20 \%)$ and pronunciation $(20 \%)$. The researcher gave a raw score (1-5 points) for each category, with points for each category then multiplied by four 
and added up for a score out of 100 points.

\section{Results}

Descriptive statistics (minimum, maximum, mean scores and standard deviations) of the PVLT across five frequency levels are presented in Table 1. A closer inspection of the mean scores for the five frequency levels revealed a more or less consistent pattern of a distinctive downwards slope from the most to the least frequent words. The results suggest that the participants showed better performance at the higher frequency levels than the lower ones, with many meeting the cut-off score of 16 out of 18 for the 2000 word level, indicating mastery at this level.

Table 1. Results of the PVLT for each frequency level

\begin{tabular}{lllll}
\hline Frequency level & Minimum & Maximum & Mean & Standard deviation \\
\hline 2,000 words & 6.00 & 18.00 & 22.98 & 8.66 \\
3,000 words & 4.00 & 16.00 & 19.01 & 8.54 \\
Academic words & 4.00 & 15.00 & 15.43 & 5.50 \\
5,000 words & 3.00 & 12.00 & 9.12 & 8.17 \\
10,000 words & 2.00 & 9.00 & 6.57 & 4.88 \\
\hline
\end{tabular}

Note. The maximum score for each frequency level is 18 points.

This is a crucial observation in the current context (see Table 1) as the participants were likely expected to encounter the target words at higher levels as at most universities where English is a widely used foreign language, the learning conditions make heavy demands on reading and writing skills. In addition, the development of a vocabulary knowledge profile at the 3,000-word level is similar to the preceding 2,000-word level which indicates a successful vocabulary learning progress. The standard deviation of the participants' cohort between the academic and the 5,000-word levels is the largest, indicating that the mean score differences between these levels are the greatest. Consequently, the difference between the means of the academic word level and the 5,000-word level is statistically significant $(r=.487, p<.001)$. However, no large difference is observed between the knowledge of the participants' performance at the other different word levels. In fact, as the statistics in Table 2 demonstrate, of the five-word frequency levels of productive vocabulary knowledge investigated there are strengths of association between the 2,000 and 3,000-word levels and speaking tasks. The diminishing link between the productive vocabulary size and speaking tasks appears at the higher frequency levels, i.e., at the academic word level and above.

Table 2. Pearson correlations between word frequency levels and speaking tasks

\begin{tabular}{llllll}
\hline Study measures & $\mathbf{2 , 0 0 0}$-word level & $\mathbf{3 , 0 0 0}$-word level & Academic word level & $\mathbf{5 , 0 0 0}$-word level & $\mathbf{1 0 , 0 0 0}$-word level \\
\hline Interview task & $.488^{* *}$ & $.575^{* *}$ & .302 & .390 & .232 \\
Conversation task & $.687^{* *}$ & $.794^{* *}$ & .467 & .211 & .141 \\
\hline
\end{tabular}

Table 3. Pearson correlations between PVLT and speaking tasks

\begin{tabular}{lll}
\hline Study measures & $\boldsymbol{r}$ & $\boldsymbol{p}$ \\
\hline PVLT & $.457^{* *}$ & $<.001$ \\
Interview task & $.732^{* *}$ & $<.001$ \\
Conversation task & $\mathbf{. 6 8 9 * *}$ & $<.001$ \\
\hline
\end{tabular}

Pearson correlations between PVLT and speaking tasks are shown in Table 3. Both interview and conversation tasks are significantly correlated with PVLT. Specifically, the interview task was strongly correlated with PVLT $(r=.732, p<.001)$ and the conversation task was moderately correlated with PVLT $(r=.689, p<.001)$. These results support the tendency that the more vocabulary the participants know, the more they produce L2 words in speaking tasks.

\section{Discussion}

The current study considered two related research questions: one, what is the participants' vocabulary size at each of the five frequency word levels covered by PVLT, and two, does the vocabulary size as measured by PVLT have the same influence on different types of speaking task. Results showed that the participants are more 
likely to produce high frequency words than low frequency words. This is as expected as they are likely to encounter high frequency words more often in their academic studies, being associated with academic language and textbook materials used within their university degree. This finding is aligned with the high scores obtained by the participants at 2,000 and 3,000 word frequency levels, and coupled with previous findings that having to know a reasonable number of lexical items in the 2,000 and 3,000 words levels, this would enable them to understand almost everything in daily conversation (Adolphs \& Schmitt, 2003; Milton, 2013; Read, 1998; Stæhr, 2009). On the other hand, the scores drop consistently from higher to lower word frequency levels, suggesting a lack of motivation or interest on the part of participants may result in their small vocabulary at lower frequency levels. It may be that the inability of the study participants to produce the least frequent lexical items is due to these items being rarely encountered in university orientated textbooks. A further factor that may contribute to this trend is the influence of the university teaching and learning preferences. That is, with limited time devoted to explicitly teaching vocabulary in the classroom, and not focusing on extensive reading, L2 learners may not increase their store of low frequent word items through such pedagogical practices.

The second research question sought to uncover any interaction between the participants' productive vocabulary size and their speaking performance, asking whether vocabulary size as measured by PVLT had the same influence on different types of speaking task. The findings reveal significant correlations between the participants' PVLT scores and the speaking tasks (see Table 3). Notably, the results indicate that, when the relationship between PVLT and the objective speaking task is given close attention, the production of vocabulary items at 2,000 and 3,000-word levels is significantly associated with the successful scores of the participants' speaking performance, i.e., in both oral tasks, and this is illustrated in Table 2. These findings provide further evidence for the findings by Uchihara and Clenton (2018) whose participants' vocabulary size at higher frequency levels contributed to their L2 speech tasks. It is helpful to look at and try to explain the strength of association between the PVLT and the participants' speaking tasks. All the words that are used in the interview and conversation tasks were from the 2,000 and 3,000 most frequent English words. This means that the words elicited from the participants reflected to a very large extent their knowledge of the 2,000 and 3,000-word levels. In effect, this explains the participants' difficulties to produce correct answers at levels higher than the 2,000 or 3,000-word levels. Clearly, current evidence suggests that to be conversant in English, an L2 learner needs to have command of the 2,000 and 3,000 most frequent words of English (De Jong, Steinel, Florijn, Schoonen, \& Hulstijn, 2012; Koizumi \& In'nami, 2013; Schmitt, 2010).

We still need to explain the absence of any significant links between the vocabulary size of low frequent words and the participants' speaking performance. That is, the present study suggests that the knowledge of infrequent words, presumably any lexical item outside the 2,000 and 3,000-word levels, may have been given little attention in the classroom setting practicing speaking. The learners could then use common words, paraphrase their intended messages and maintain the flow of conversation rather than use infrequent or sophisticated vocabulary. Arguably, the limited opportunities for oral vocabulary revision can be enhanced in spoken rather than written mode due to the small size of oral productive vocabulary.

While such speaking practice is less useful for vocabulary learning, it may help the learners to avoid empty pauses and hesitation in their EFL oral classrooms. It is nevertheless acknowledged that in the absence of some retrospective information about how the learners performed speaking in the classroom, the above explanations remain speculative. Ultimately, the present study offers sufficient evidence to suggest that the participants' productive vocabulary size did significantly contribute to their speaking scores, reflecting the improvement in both interview and conversation performance.

\section{Conclusion and Implications for Language Pedagogy}

This study sought to establish a relationship between learners' productive vocabulary knowledge and their oral performance. The results revealed that knowledge of the words at the 2,000 and 3,000-word frequency levels was required for participants to perform competently in several speaking tasks. Such vocabulary size is considered here to have predictive value of the knowledge required for competent L2 speech. It is suggested that the acquisition of an EFL vocabulary for oral programs should require ongoing explicit pedagogical emphasis on an adequate command of 2,000 and 3,000-word frequency to facilitate basic EFL speaking success. In terms of the high value put on developing vocabulary knowledge beyond the high frequency levels within communicative classrooms in which oral input is a more central element, it is worth promoting vocabulary gains through additional authentic listening texts. To meet this goal a balanced approach is needed where vocabulary learning through listening should be supplemented by explicit teaching and extensive reading to achieve the most impressive vocabulary gains on a long-term basis. Overall, the findings of this study are noteworthy as establishing the present participants' productive vocabulary size via the PVLT serves as a robust metric for 
diagnosing speaking performance. With these caveats, the PVLT as the assessment measure used to compare participants' performance on different speaking tasks enhances our understanding of learners' productive vocabulary profile. Moreover, eliciting spoken data through a single task as investigated by Uchihara and Clenton (2018) was not possible in the current study as it would have threatened its ecological validity. Therefore, a combination of production tasks such as oral interview and conversation in different communicative forms was justified and undertaken to minimize the limitations posed by non-lexically rich spoken language.

The current study has some crucial limitations that have to be acknowledged. One of them relates to the study sample as all participants were drawn from a single university. Hence, replications of this study in different institutions in SA are needed to confirm our findings. Also, the present study used only male students and another variable, such as gender, may explore the significance of the effect of vocabulary size on speaking performance and therefore increase the findings' generalisability. Further research may thus be needed to determine the effectiveness of providing support to the acquisition of productive vocabulary knowledge and thus to the improvement of L2 learners' speaking performance.

\section{References}

Alharthi, T. (2016). Adult learners' acquisition of vocabulary knowledge from explicit listening: A multidimensional construct. International Journal of Multidisciplinary and Current Research, 4, 626-636.

Alharthi, T. (2018). Minding the gap in vocabulary knowledge: Incidental focus on collocation through reading. Arab World English Journal, 9(2), 3-22. https://doi.org/10.24093/awej/vol9no2.1

Alharthi, T. (2019). Formulaic sequences as predictors of listening comprehension: A contribution to research into incidental learning of collocations. Asian EFL Journal, 23, 180-190.

Barfield, A. (2003). Collocation recognition and production: Research insights. Tokyo: Chuo University.

Bishop, H. (2004). Noticing formulaic sequences: A problem of measuring the subjective. LSO Working Papers in Linguistics, 4, 15-19.

Blass, L., Vargo, M., \& Folse, K. (2014). Pathways 4 reading, writing and critical thinking. Boston, MA: National Geographic Learning.

Boers, F. (2000). Metaphor awareness and vocabulary retention. Applied Linguistics, 24, 553-571. https://doi.org/10.1093/applin/21.4.553

Boers, F., Demecheleer, M., Coxhead, A., \& Webb, S. (2014). Gauging the effects of exercise on verb-noun collocations. Language Teaching Research, 18, 54-74. https://doi.org/10.1177/1362168813505389

Chen, Y., \& Lai, H. (2013). EFL learners' awareness of metonymy-metaphor continuum in figurative expressions. Language Awareness, 21, 235-248. https://doi.org/10.1080/09658416.2011.598527

Choi, S. (2017). Processing and learning of enhanced English collocations: An eye movement study. Language Teaching Research, 21(3), 403-426. https://doi.org/10.1177/1362168816653271

Cieślicka, A. (2006). Literal salience in on-line processing of idiomatic expressions by second language learners. Second Language Research, 22, 115-144. https://doi.org/10.1191/0267658306sr263oa

Collins Cobuild Dictionary of Idioms (2nd ed.). (2002). Glasgow: Harper Collins.

Conklin, K., \& Schmitt, N. (2008). Formulaic sequences: Are they processed more quickly than nonformulaic language by native and nonnative speakers? Applied Linguistics, 29, 72-89. https://doi.org/10.1093/applin/amm022

Cooper, T. (1999). Processing of idioms by L2 learners of English. TESOL Quarterly, 33, 233-262. https://doi.org/10.2307/3587719

Cornell, A. (1999). Idioms: An approach to identify major pitfalls for learners. IRAL, 37, 1-21. https://doi.org/10.1515/iral.1999.37.1.1

Coxhead, A. (2015). Replication research in pedagogical approaches to formulaic sequences: Jones \& Haywood (2004) and Alali \& Schmitt (2012). Language Teaching, 51(1), 1-11. https://doi.org/10.1017/S0261444815000221

Davies, M. (2008). The corpus of contemporary American English: 520 million words, 1990-present. Retrieved April 13, 2019 from http://corpus.byu.edu/coca

Dörnyei, Z., Durow, V., \& Zahran, K. (2004). Individual differences and their effects on formulaic sequence acquisition. In N. Schmitt (Ed.), Formulaic sequences (pp. 87-106). Amsterdam: John Benjamins. 
https://doi.org/10.1075/11lt.9.06dor

Durrant, P., \& Schmitt, N. (2010). Adult learners' retention of collocations from exposure. Second Language Research, 26, 163-188. https://doi.org/10.1177/0267658309349431

Fernando, C., \& Flavell, R. (1981). On idiom: Critical views and perspectives. Exeter Linguistic Studies, 5.

Folse, K. (2006). The effect of type of written exercise on L2 vocabulary retention. TESOL Quarterly, 40, $273-293$. https://doi.org/10.2307/40264523

González, F. B., \& Schmitt, N. (2015). How much collocation knowledge do L2 learners have? The effects of frequency and amount of exposure. ITL International Journal of Applied Linguistics, 166, 94-126. https://doi.org/10.1075/itl.166.1.03fer

Grant, L., \& Bauer, L. (2004). Criteria for re-defining idioms: Are we barking up the wrong tree? Applied Linguistics, 25, 38-61. https://doi.org/10.1093/applin/25.1.38

Hill, J. (2000). Revising priorities: From grammatical failure to collocational success. In M. Lewis (Ed.), Teaching collocation: Further developments in the lexical approach (pp. 47-69). Hove, UK: Language Teaching Publications.

Howarth, P. (1996). Phraseology in English academic writing: Some implications for language learning and dictionary making. Tubingen, Germany: Max Niemeyer. https://doi.org/10.1515/9783110937923

Hsu, J.-Y., \& Chiu, C.-Y. (2008). Lexical collocations and their relation to speaking proficiency of college EFL learners in Taiwan. Asian EFL Journal, 10, 181-204.

Katsarou, E. C. (2013). Grasping the nettle of L2 idiomaticity puzzle: The case of idiom identification and comprehension during L2 reading by Greek learners of English. In W. Lavidas, T. Alexiou \& A. M. Sougari (Eds.), Major Trends in Theoretical and Applied Linguistics 3: Selected Papers from the 20th ISTAL (pp. 143-158). London: Walter de Gruyter.

Keshavarz, M. H., \& Salimi, H. (2007). Collocational competence and cloze test performance: A study of Iranian EFL learners. International Journal of Applied Linguistics, 17, 81-92. https://doi.org/10.1111/j.1473-4192.2007.00134.x

Kim C. (2016). L2 learners' recognition of unfamiliar idioms composed of familiar words. Language Awareness, 25(1-2), 89-109. https://doi.org/10.1080/09658416.2015.1122025

Koizumi, R., \& In'nami, Y. (2013). Vocabulary knowledge and speaking proficiency among second language learners from novice to intermediate levels. Journal of Language Teaching and Research, 4, 900-913. https://doi.org/10.4304/jltr.4.5.900-913

Laufer, B. (2009). Second language vocabulary acquisition from language input and from form focused activities. Language Teaching, 42, 341-354. https://doi.org/10.1017/S0261444809005771

Laufer, B., \& Aviad-Levitzky, T. (2017). What type of vocabulary knowledge predicts reading comprehension: Word meaning recall or word meaning recognition? The Modern Language Journal, 101, 729-741.

Laufer, B., \& Goldstein, Z. (2004). Testing vocabulary knowledge: Size, strength, and computer adaptiveness. Language Learning, 54, 399-436. https://doi.org/10.1111/j.0023-8333.2004.00260.x

Le-Thi, D., Rodgers, M. P. H., \& Pellicer-Sánchez, A. (2017). Teaching formulaic sequences in an English-language class: The effects of explicit instruction versus coursebook instruction. TESL Canada Journal, 34(3), 111-139. https://doi.org/10.18806/tesl.v34i3.1276

Macis, M., \& Schmitt, N. (2016). Not just "small potatoes": Knowledge of the idiomatic meanings of collocations. Language Teaching Research, 21(3), 321-340. https://doi.org/10.1177/1362168816645957

Macis, M., \& Schmitt, N. (2017). The figurative and polysemous nature of collocations and their place in ELT. ELT Journal, 71(1), 50-59. https://doi.org/10.1093/elt/ccw044

Martinez, R., \& Murphy, V. A. (2011) Effect of frequency and idiomaticity on second language reading comprehension. TESOL Quarterly, 45(2), 267-290. https://doi.org/10.5054/tq.2011.247708

Matthews, J. (2018). Vocabulary for listening: Emerging evidence for high and mid-frequency vocabulary knowledge. System, 72, 23-36. https://doi.org/10.1016/j.system.2017.10.005

Matthews, J., \& Cheng, J. (2015). Recognition of high frequency words from speech as a predictor of L2 listening comprehension. System, 52, 1-13. https://doi.org/10.1016/j.system.2015.04.015 
Meunier, F. (2012). Formulaic language and language teaching. Annual Review of Applied Linguistics, 32, 111129. https://doi.org/10.1017/S0267190512000128

Milton, J., Wade, J., \& Hopkins, N. (2010). Aural word recognition and oral competence in a foreign language. In R. Chacón-Beltrán, C. Abello-Contesse \& M. Torreblanca-López (Eds.), Further insights into non-native vocabulary teaching and learning (pp. 83-98). Bristol: Multilingual Matters. https://doi.org/10.21832/9781847692900-007

Moon, R. (1998). Fixed expressions and idioms in English. Oxford: Clarendon Press.

Nation, I. S. P. (2001). Vocabulary learning in another language. Cambridge: Cambridge University Press. https://doi.org/10.1017/CBO9781139524759

Nation, I. S. P. (2013). Learning vocabulary in another language (2nd ed.). Cambridge: Cambridge University Press. https://doi.org/10.1017/CBO9781139858656

Nation, I. S. P., \& Beglar, D. (2007). A vocabulary size test. The Language Teacher, 31(7), 9-13.

Nesselhauf, N. (2003). The use of collocations by advanced learners of English and some implications for teaching. Applied Linguistics, 24(2), 223-242. https://doi.org/10.1093/applin/24.2.223

Nesselhauf, N. (2005). Collocations in a learner corpus. Amsterdam: John Benjamins. https://doi.org/10.1075/scl.14

Park, J., \& Chon, Y. (2018). EFL learners' knowledge of high-frequency words in the comprehension of idioms: A boost or a burden? RELC Journal, 7, 1-16. https://doi.org/10.1177/0033688217748024

Pellicer-Sánchez, A. (2015). Learning L2 collocations incidentally from reading. Language Teaching Research, 21(3), 381-402 https://doi.org/10.1177/1362168815618428

Peters, E. (2012). Learning German formulaic sequences: The effect of two attention-drawing techniques. The Language Learning Journal, 40, 65-79. https://doi.org/10.1080/09571736.2012.658224

Pigada, M., \& Schmitt, N. (2006). Vocabulary acquisition from extensive reading: A case study. Reading in a Foreign Language, 18, 1-28.

Schmitt, N. (2008). Instructed second language vocabulary learning. Language Teaching Research, 12, 329-363. https://doi.org/10.1177/1362168808089921

Schmitt, N. (2010). Researching vocabulary: A vocabulary research manual. Basingstoke UK: Palgrave Macmillan. https://doi.org/10.1057/9780230293977

Schmitt, N., Schmitt, D., \& Clapham, C. (2001). Developing and exploring the behaviour of two new versions of the Vocabulary Levels Test. Language Testing, 18(1), 55-88. https://doi.org/10.1177/026553220101800103

Sinclair, J. (1991) Corpus, concordance, collocation. Oxford: Oxford University Press.

Siyanova, A., \& Martinez, R. (2015). The idiom principle revisited. Applied Linguistics, 36(5), 549-569.

Siyanova, A., \& Schmitt, N. (2007). Native and nonnative use of multi-word vs. one-word verbs. International Review of Applied Linguistics, 45, 119-139. https://doi.org/10.1515/IRAL.2007.005

Sonbul, S., \& Schmitt, N. (2013). Explicit and implicit lexical knowledge: Acquisition of collocations under different input conditions. Language Learning, 63, 121-159. https://doi.org/10.1111/j.1467-9922.2012.00730.x

Staehr, L. S. (2009). Vocabulary knowledge and advanced listening comprehension in English as a foreign language. Studies in Second Language Acquisition, 31, 577-607. https://doi.org/10.1017/S0272263109990039

Teng, F. (2019). Retention of new words learned incidentally from reading: Word exposure frequency, L1 marginal glosses, and their combination. Language Teaching Research, 22, 1-28. https://doi.org/10.1177/1362168819829026

Türker, E. (2016). The role of L1 conceptual knowledge and frequency in the acquisition of L2 metaphorical expressions. Second Language Research, 32(1), 25-48. https://doi.org/10.1177/0267658315593336

Uchihara, T., \& Saito, K. (2016). Exploring the relationship between productive vocabulary knowledge and second language oral ability. The Language Learning Journal, 47, 1-12. https://doi.org/10.1080/09571736.2016.1191527

Uchihara, T., \& Clenton, J. (2018). Investigating the role of vocabulary size in second language speaking ability. 
Language Teaching Research, 22, 1-17. https://doi.org/10.1177/1362168818799371

Underwood, G., Schmitt, N., \& Galpin, A. (2004). The eyes have it: An eye-movement study into the processing of formulaic sequences. In N. Schmitt (Ed.), Formulaic sequences (pp. 153-172). Amsterdam: John Benjamins. https://doi.org/10.1075/1llt.9.09und

van Zeeland, H., \& Schmitt, N. (2013). Incidental vocabulary acquisition through L2 listening: A dimensions approach. System, 41(3), 609-624. https://doi.org/10.1016/j.system.2013.07.012

Wang, Y., \& Treffers-Daller, J. (2017). Explaining listening comprehension among L2 learners of English: The contribution of general language proficiency, vocabulary knowledge and metacognitive awareness. System, 65, 139-150. https://doi.org/10.1016/j.system.2016.12.013

Webb, S. (2005). Receptive and productive vocabulary learning: The effects of reading and writing on word knowledge. Studies in Second Language Acquisition, 27, 33-52. https://doi.org/10.1017/S0272263105050023

Webb, S., \& Chang, A. (2015). Second language vocabulary learning through extensive reading: How does frequency and distribution of occurrence affect learning? Language Teaching Research, 18, 1-20. Retrieved from http://tr.sagepub.com/content/early/2014/11/27/1362168814559800.full.pdf + html

Wolter, B., \& Gyllstad, H. (2012). Frequency of input and L2 collocational processing. Studies in Second Language Acquisition, 35, 451-482. https://doi.org/10.1017/S0272263113000107

Wood, D. (2006). Uses and functions of formulaic sequences in second language speech: An exploration of the foundations of fluency. Canadian Modern Language Review, 63(1), 13-33. https://doi.org/10.3138/cmlr.63.1.13

Wray, A. (2002). Formulaic language and the lexicon. Cambridge: Cambridge University Press. https://doi.org/10.1017/CBO9780511519772

Zyzik, E. (2011). Second language idiom learning: The effects of lexical knowledge and pedagogical sequencing. Language Teaching Research, 15, 413-433. https://doi.org/10.1177/1362168811412025

\section{Copyrights}

Copyright for this article is retained by the author, with first publication rights granted to the journal.

This is an open-access article distributed under the terms and conditions of the Creative Commons Attribution license (http://creativecommons.org/licenses/by/4.0/). 